\title{
ENSINO DE FILOSOFIA, FORMAÇÃ̃o E INTERDISCIPLINARIDADE
}

\author{
Cícero Oliveira ${ }^{1}$ \\ Universidade Federal do Recôncavo da Bahia (UFRB) \\ (D) https://orcid.org/0000-0002-4517-8510
}

\begin{abstract}
RESUMO:
O texto apresenta e discute o tema da interdisciplinaridade com foco especial sobre as ciências humanas a partir de dois movimentos articulados. (a) Na primeira parte dedicamo-nos à elaboração do problema da fragmentação cultural (que nos leva ao desafio da interdisciplinaridade) por alusão à "ambiência moderna" como modo historicamente determinado de relação com a cultura e o saber, particularmente motivado pelo que Thomas Kuhn chama de "ciência normal". (b) Na segunda parte, e à luz de tais considerações históricas e epistemológicas da subjetivação moderna, importa apontar os desafios implicados no projeto de uma formação interdisciplinar e ao mesmo tempo sinalizar para alguma estratégia de enfrentamento do problema da fragmentação cultural - encarado na condição de fenômeno histórico profundamente ancorado. A ampla fragmentação cultural, que as estratégias múltiplas de abordagem "interdisciplinar" pretendem combater no cenário da formação escolar, é especialmente experimentada como compartimentalização disciplinar do currículo em geral e das ciências humanas aqui miradas. Neste contexto, sustentamos que o componente curricular de filosofia, mas também o espírito filosófico pedagogicamente dilatado compõem respectivamente formação e estratégia epistemológica promissoras para o enfrentamento da fragmentação cultural no registro da interdisciplinaridade.
\end{abstract}

PALAVRAS-CHAVE: Modernidade; Fragmentação cultural; Interdisciplinaridade; Ciências humanas.

\section{TEACHING OF PHILOSOPHY, FORMATION AND INTERDISCIPLINARITY}

\begin{abstract}
:
The text presents and discusses the theme of interdisciplinarity with special focus on the human sciences from two articulated movements. (A) In the first part we are dedicated to the elaboration of the problem of cultural fragmentation (which brings us to the interdisciplinary challenge) by allusion to the "modern ambience" as a historically determined way of relating to culture and knowledge, for what Thomas Kuhn calls "normal science." (B) In the second part, and starting of such historical and epistemological considerations of modern subjectivation, it is important to point out the challenges involved in the design of an interdisciplinary formation and at the same time signaling to some strategy of facing the problem of "cultural fragmentation" - regarded as a deeply anchored historical phenomenon. The broad "cultural fragmentation" that multiple interdisciplinary strategies aim to combat in the school setting is especially experienced as a disciplinary compartmentalization of the curriculum in general and of the human sciences we are looking at here. In this context, we maintain that the curricular component of philosophy, but also the philosophical spirit pedagogically dilated, respectively, constitute a promising epistemological formation and strategy for confronting cultural fragmentation in the interdisciplinarity register.
\end{abstract}

KEYWORDS: Modernity; Cultural fragmentation; Interdisciplinarity; Human sciences.

\footnotetext{
${ }^{1}$ Professor adjunto do curso de licenciatura em Filosofia do Centro de Formação de Professores (CFP) da Universidade Federal do Recôncavo da Bahia (UFRB), Bahia - Brasil. E-mail: cicerojsoliveira@ufrb.edu.br
}

OLIVEIRA, Cícero. Ensino de filosofia, formação e interdisciplinaridade. Griot : Revista de Filosofia, Amargosa/Bahia, v.17, n.1, p.193-203, junho/2018. 


\title{
Ambiência moderna e fragmentação cultural
}

Num ensaio acerca do potencial formativo, mas também dos desafios implicados no ensino de filosofia em decorrência da tensão entre o duplo recurso à "história do pensamento filosófico" e à "força interrogante" da "Filosofia"2, Franklin Leopoldo e Silva elabora como precisão cirúrgica o problema ensejado pelo caráter fragmentário da cultura moderna:

\begin{abstract}
A fragmentação da experiência não é acidental nem deve ser tratada apenas psicologicamente. Os exercícios que visam levar o estudante à ordem do discurso filosófico possuem a finalidade de compreensão e ordenação reflexiva da experiência. Este tipo de inteligibilidade distinguese da racionalidade instrumental - ambiência mais natural do sujeito no mundo moderno -, primeiramente por levar a uma tomada de consciência da própria fragmentação. A objetivação da experiência é objetivação da fragmentação, na medida em que refletir sobre as relações entre sujeito e cultura é antes de mais nada pôr-se em condições de reconhecer a fragmentação do sujeito num mundo cultural fragmentado. Somente dessa maneira é que se poderão ser criadas condições para pensar criticamente a própria fragmentação. Para que isso ocorra é preciso que a fragmentação seja reconhecida como determinação histórica: isto já é parte da reflexão propriamente filosófica, pois é uma abordagem filosófica da história. (LEOPOLDO E SILVA, 1993, p. 803. Nossos grifos)
\end{abstract}

No fracionamento estanque e impermeável das experiências com a cultura, está em jogo (dentre outras coisas) a instituição de um critério cientificista, majoritário, normativo e taxativo de relação com o saber ou uma "racionalidade" que reivindica o privilégio de sua posição a partir do "progresso" com o qual mantém pouco distanciamento crítico.

O que a imersão num tratamento fracionado da realidade nos deixa em poucas condições de entrever é que os fenômenos naturais e sociais são de tal complexidade que não se submetem à rígida abordagem paradigmática e disciplinar a que são irredutíveis. Contra o pano de fundo dessa fragmentação, o aspecto mais decisivo da estratégia epistemológica e pedagógica da interdisciplinaridade consiste em admitir que o fracionamento não decorre da realidade mesma, mas dos recursos que concebemos para o seu trato cognitivo.

Daí que antes de seguirmos na trilha de uma possível equação ao problema de uma cultura determinada pela fragmentação e pela compartimentalização do saber, exploraremos minimante a construção histórica da "ambiência moderna" que a tornou possível. Se é verdade, como defende Franklin Leopoldo e Silva, que a compartimentalização da cultura não pode ser tratada apenas na dimensão do

2 Este duplo recurso, afirma o autor, "pode nos mostrar que, independentemente do recorte [histórico] que se opere, devemos sempre buscar naquilo que foi pensado o que nos faz pensar. Essa é a vantagem da abertura histórica da Filosofia, mas tal vantagem só aparecerá concretamente na prática do ensino se ela for elaboradora no sentido de extrair das experiências históricas do pensamento os meios para ordenar criticamente a experiência fragmentária da realidade da cultura." (LEOPOLDO E SILVA, 1993, p. 803)

OLIVEIRA, Cícero. Ensino de filosofia, formação e interdisciplinaridade. Griot : Revista de Filosofia, Amargosa/Bahia, v.17, n.1, p.193-203, junho/2018. 
imediatamente vivido e que tal "ambiência" (o da segmentação cultura) é, na verdade, apenas a instância em que reverberam injunções históricas mais amplas, então não é inoportuno interrogarmo-nos aqui sobre as mais decisivas destas injunções. Tanto mais que os esforços de resistência supõem a abordagem e a reflexão a respeito de seus significados.

A fragmentação como modo de "subjetivação epistemológica" de certo modo é genealogizada por Thomas Kuhn (1922-1996), filósofo e historiador da ciência americano, no célebre ensaio $A$ estrutura das revoluções científicas (1963). Dentro do feixe de razões que respondem pela ordenação das experiências e da cultura modernas, a título de indicações gerais, consideraremos apenas a emergência e a natureza da ciência como a conhecermos; fato que seguramente figura entre os eventos modernos mais decisivos para a inflexão radical no âmbito da cultura, especialmente no concerne à organização do saber.

Nesse ensaio em que anuncia o propósito de desenvolver uma "concepção de ciência historicamente orientada" (KUHN, 2003, p. 15), Kuhn examina a origem, a natureza e dinâmica científicas e reconhece, dentre outros, três aspectos que nos são particularmente caros para caracterização mais geral da ciência consoante ao modo como temos em mira. Para Kuhn, a ciência que nasce na modernidade é marcada por três aspectos mutuamente imbricados ou vinculados entre si enquanto é: (i) "paradigmática", (ii) altamente especializada (iii) e articuladora de uma compreensão historicamente decisiva de progresso.

A fim de otimizarmos o uso do espaço disponível, examinemos com brevidade este bloco que aspectos.

(i) A ciência é paradigmática. Já no prefácio ao ensaio $A$ estrutura das revoluções científicas, Kuhn relata que a decisiva elaboração do conceito de "paradigmas" foi possibilitada pelo empenho comparativo entre as práticas metodológicas das ciências sociais e das ciências naturais $\mathrm{O}$ exame decorreu da forte impressão que lhe causou a diferença flagrante entre o número e a extensão dos desacordos expressos e existentes entre os cientistas sociais no tocante à natureza dos métodos e dos problemas científicos legítimos, relativamente aos cientistas naturais entre os quais o próprio Kuhn fora formado.

O historiador da ciência nos dá conta de que foi precisamente no contexto da dúvida quanto a ideia tradicionalmente sustentada de que os praticantes das ciências naturais tenham respostas mais permanentes para suas questões, que elaborou o conceito de "paradigmas". Na formulação de Thomas Kuhn, a despeito de uma firmeza discutível,

De algum modo, a prática da Astronomia, da Física, da Química ou da Biologia normalmente não evocam as controvérsias sobre fundamentos que atualmente parecem endêmicas entre, por exemplo, psicólogos ou sociólogos. A tentativa de descobrir a fonte dessa diferença levou-me ao reconhecimento do papel desempenhado na pesquisa científica por aquilo que, desde então, chamo de "paradigmas". Considero "paradigmas" as realizações científicas universalmente reconhecidas que, durante algum tempo, fornecem problemas e soluções modelares para uma comunidade de praticantes de uma ciência. Quando esta peça do meu quebra-cabeça se encaixou no seu lugar, um esboço preliminar deste ensaio emergiu rapidamente. (KUHN, 3003, p. 12-13)

OLIVEIRA, Cícero. Ensino de filosofia, formação e interdisciplinaridade. Griot : Revista de Filosofia, Amargosa/Bahia, v.17, n.1, p.193-203, junho/2018. 
Em suma, na terminologia kuhniana podemos dizer que "paradigmas" são tradições determinadas e singulares de pesquisas científicas cujas avaliações não podem ser expressas pelo recurso ou mediação de qualquer paradigma pregresso ou atual. Se cada paradigma implica em colocar de determinado modo os problemas a serem resolvidos, um paradigma não pode ser legitimamente julgado na referência a outro. Não é outro o sentido de "incomensurabilidade" que Kuhn vincula ao de "paradigmas".

Nos termos de Kuhn, "os paradigmas adquirem seu status porque são mais bem sucedidos que seus competidores na resolução de alguns problemas que o grupo de cientistas reconhece como grave." (KUHN, 2003, p. 44).

O empenho próprio da "ciência normal", ou da ciência que procede por paradigmas, consiste em submeter os fenômenos ao crivo das predições paradigmáticas. Assumir um paradigma significa assumir um critério de escolha, colocação e modos de resolução dos problemas (métodos) dotados de forma única de solução possível enquanto vigorar a escolha do paradigma. Daí que o autor registre como traço decisivo da ciência que procede por paradigmas o fato de ser uma promessa de sucesso no limite das condições fixadas: a ciência paradigmática é a "tentativa de forçar a natureza a encaixar-se dentro dos limites preestabelecidos e relativamente inflexíveis fornecidos pelo paradigma." (KUHN, 2003, p. 45).

(ii) A ciência é altamente especializada. Tomas Kuhn observa que a ciência é sempre especializada e cumulativa na ordem interna de um paradigma, e porque não se orienta pelo objetivo de trazer à tona novas espécies de fenômenos, estes amiúde se lhes escapa quando não se enquadram parcial ou totalmente nos limites do paradigma encarado como quadro conceitual de percepção do mundo.

A pesquisa "científica normal" se dirige pelo empenho paradigmático de vinculação, de indexação das teorias aos fenômenos por elas circunstanciados; seu objetivo precípuo consiste em dilatar o campo de aplicação do "paradigma" e/ou aumentar a precisão de uma aplicação já realizada. A cumulatividade na ordem interna ao paradigma, e, portanto, no registro de uma especialização crescente, é, assim, a segunda característica da ciência normal que convêm destacar.

\begin{abstract}
As áreas investigadas pela ciência normal são certamente minúsculas; ela restringe drasticamente a visão do cientista. Mas essas restrições, nascidas da confiança no paradigma, revelaram-se essenciais para o desenvolvimento da ciência. Ao concentrar a atenção numa faixa de problemas relativamente esotéricos, o paradigma força os cientistas a investigar alguma parcela da natureza com uma profundidade e de uma maneira tão detalhada que de outro modo seriam inimagináveis. [....] Uma vez liberada da necessidade de reexaminar constantemente seus fundamentos em vista da aceitação de um paradigma comum, permite a seus membros concentrarem-se exclusivamente nos fenômenos mais esotéricos e sutis que lhes interessam. Inevitavelmente, isso aumenta tanto a competência como a eficácia com as quais o grupo como um todo resolve novos problemas. (KUHN, 2003, p. 65/206)
\end{abstract}

(iii) A ciência é articuladora de uma compreensão historicamente decisiva de progresso. Finalmente, operando nos termos acima definidos, isto é, enquanto (i) promessas de atualizações de determinados paradigmas e (ii) acúmulo especializado e 
refinado de conhecimento na ordem interna dos paradigmas, a ciência moderna termina por indexar-se ao conceito de "progresso" como o resultado incontornável e mais emblemático de seu desenvolvimento.

Um dos traços mais notórios acerca do conceito de "progresso" nesse contexto é o fato de que, mais do que simples juízo de fato ou de constatação (problemática) do desenvolvimento científico, o "progresso" científico traduz um juízo de valor à luz do qual a modernidade e a contemporaneidade se auto compreendem. Neste contexto "progresso" é também valor que a sociedade científica infere de si mesma e padrão epistemológico de julgamento; critério de inclusão e exclusão para o cultivo da relação com o saber. No domínio da "ciência normal" a própria "fragmentação" estanque do saber é compreendida como um dado, um estágio incontornável e necessário do "progresso" histórico do conhecimento ${ }^{3}$. Em suma, quisemos destacar aqui que a "ambiência natural do sujeito moderno" da qual partirmos para a elaboração do desafio da interdisciplinaridade que se nos impõe, decorre de modo fundamental da construção histórica segundo a qual o "progresso" é ideal a ser perseguido, de modo exemplar, no domínio do saber majoritariamente instituído como paradigmático, instrumental, altamente especializado e fragmentado.

Este modo originalmente moderno de situar-se no mundo, relacionar-se e avaliar o saber, que tem sido encarado e assumido simultaneamente como fato, valor e padrão de excelência, é um dado histórico constitutivo de nossa subjetivação epistemológica e cultural que de modo algum pode ser desconsiderado nos desafios representados pela interdisciplinaridade como estratégia de formação. E isso, quer nas ciências naturais examinadas por Kuhn, quer nas ciências humanas. Aqui chegamos à inflexão que a segunda parte pretende tratar.

\section{As ciências humanas e o desafio da interdisciplinaridade}

De modo flagrante e decisivo, a fragmentação como determinação histórica se perpetua no nível da formação e da vivência escolar ordenadas como modo de subjetivação epistemológica e cultural.

A escola é a mais destacada ambiência social de formação por imersão nas experiências fragmentárias no domínio da cultura. É na escola que se fazem sentir, como em nenhuma outra parte, as profundas determinações das experiências não comunicadas entre os setores do saber isolados uns dos outros pelo rígido tratamento disciplinar.

A esta altura, e em razão do que procuramos desenvolver na primeira parte, deveria estar claro que a dificuldade de comunicação entre as disciplinas do currículo não deve ser simples e taxativamente referida como problema técnico de planejamento educacional. $O$ curto alcance de semelhante visão costuma induzir a medidas malsucedidas de implementação da interdisciplinaridade e da contextualização dos saberes escolares enquanto respalda-se em considerações

3 Ao contrário, Tomas Kuhn infere que a reconsideração da estrutura essencial da natureza e da evolução científica nos impõe uma inflexão fundamental acerca da noção de "progresso" em ciência. É preciso ver o progresso da ciência em geral não tanto como acúmulo gradativo de novos dados gnosiológicos, quanto como progresso contraditório marcado pelas "revoluções" do pensamento. Haveria pois que falar de progresso ateleológico na ciência.

OLIVEIRA, Cícero. Ensino de filosofia, formação e interdisciplinaridade. Griot : Revista de Filosofia, Amargosa/Bahia, v.17, n.1, p.193-203, junho/2018. 
demasiadamente formais e técnicas, pouco aptas a fazer frente à profunda compartimentalização do currículo e à exterioridade recíproca da formação disciplinar de tendências rígidas.

Quaisquer que sejam as estratégias de interdisciplinaridade, não se pode perder de vista o fato de que a separação mesma das disciplinas no âmbito do currículo escolar é algo que passam pelo modo como a modernidade e contemporaneidade no modo como se constituíram e se constituem histórica e culturalmente.

Indicada minimamente a correlação entre a ambiência moderna e o domínio da formação escolar atual, passaremos agora ao problema precípuo desta seção.

Que é interdisciplinaridade e como pode ser de algum modo viabilizada no âmbito das ciências humanas, isto é, na comunicação entre os componentes curriculares de história, geografia, sociologia e filosofia?

Quando na célebre obra $A$ condição humana (1958) Hannah Arendt empreende um exame fenomenológico da ação no contexto geral das atividades humanas fundamentais, destaca que os infortúnios advindos de sua imprevisibilidade e irreversibilidade constitutivas são redimidos por uma qualidade ou por um remédio interno à própria ação, qual seja, a faculdade ou o ato de perdoar.

À sobra desta imagem exemplar, pretendemos defender que, no tocante à fragmentação disciplinar, as ciências humanas (história, geografia, sociologia e filosofia) carregam em si as condições de sua redenção: a inflexão do curso fracionado do saber na direção oposta da formação interdisciplinar. Mais precisamente tentaremos sustentar que a filosofia, mas também a disposição ou o espírito filosófico alargado, é unidade catalisadora de dois predicados requeridos pela estratégia pedagógico-epistemológica da interdisciplinaridade. Ao tempo em que destacaremos ainda que a filosofia, um modo próprio de relação com o saber, não pode ser reduzida a estratégia pedagógica no âmbito de uma formação marcadamente disciplinar.

(i) Formação interdisciplinar. É hora de respondermos a primeira pergunta: o que é interdisciplinaridade? A palavra interdisciplinaridade refere um modo de trabalhar o conhecimento (ensino-aprendizagem) orientado pela reintegração dos aspectos que ficaram isolados ou dispersos em razão de certo tratamento dito disciplinar. O que se busca com esse expediente epistemológico e pedagógico é justamente uma visão não fragmentada, ampla e por isso mesmo mais adequada à realidade (em especial no que concerne a certos temas ${ }^{4}$ ). Em suma, a interdisciplinaridade busca compensar a fragmentação do saber que decorre não da realidade, mais dos meios que dispomos para conhecê-la. Em última análise, o que a interdisciplinaridade busca recompor, do ponto de vista cognitivo, é a própria realidade em sua irredutível complexidade.

$\mathrm{O}$ empenho de desfragmentação das experiências e dos diferentes campos de conhecimento persegue as mútuas contribuições, os pontos de convergência e as

4 Trata-se dos chamados temas transversais, ou seja, temas cujos estudos requerem uma abordagem especialmente ampla e o mais possivelmente variada que aponte e examine convergências e confronte divergências, nos níveis dos saberes escolares e não escolares, acadêmicos e não acadêmicos. Invariavelmente tais são os casos de temas como ética, sexualidade, poder, violência, meio ambiente, trabalho, consumismo e as questões racial e social dentre outras. Veremos abaixo que a "filosofia" não pode ser incluída entre os temas transversais sem prejuízo para si, enquanto componente curricular da formação, mas também para a própria "formação interdisciplinar" como um todo.

OLIVEIRA, Cícero. Ensino de filosofia, formação e interdisciplinaridade. Griot : Revista de Filosofia, Amargosa/Bahia, v.17, n.1, p.193-203, junho/2018. 
tensões nas várias áreas no plano de uma abordagem conjunta. Este empenho epistemológico de estudo dos fenômenos em sua globalidade, estipula, portanto, os termos mesmos da relação não insulada entre as disciplinas que é almejada pela interdisciplinaridade.

(ii) Qualidades filosóficas indispensáveis à interdisciplinaridade. Isso posto, prossigamos agora com nossa hipótese acerca da filosofia no tocante à formação interdisciplinar: situadas além da relação aquisitivo-progressista com o saber e da racionalidade instrumental que norteia a "ciência normal", as dimensões (a) críticoreflexiva e (b) a transversalidade, que são marcos radicalmente filosóficos da relação com o saber, constituem qualidades inescapáveis a qualquer empenho de formação interdisciplinar.

(a) Dimensão crítico-reflexiva da filosofia. Rigorosamente, a consideração da separação ou da fragmentação como determinação histórica é algo de que nem mesmo a filosofia, a despeito de sua "força interrogante", pode de todo escapar. Daí que se queremos apostar no potencial crítico-reflexivo do filosofar como estratégia de resistência à compartimentalização moderna dos saberes e sua subjetivação epistemológica, precisamos antes de tudo moderar o entusiasmo filosófico mais imediato e reforçar a atenção quanto às possibilidades de contribuição de seu potencial crítico-formativo:

\footnotetext{
A Filosofia é uma dimensão da cultura e sofre igualmente da fragmentação que a afeta. A diferença é que, para a Filosofia, esta própria situação é um tema e uma ocasião de reflexão, enquanto para as ciências é um dado que revela o progresso histórico do conhecimento. $\mathrm{O}$ importante é notar que a dispersão curricular reflete a separação das instâncias situacionais, e a Filosofia pode, a partir daí, questionar a separação interrogando as causas, desenvolvimentos e consequências do progresso histórico, e refletir acerca da maneira como a fragmentação repercute na consciência histórica do homem contemporâneo. E pode fazê-lo precisamente porque nela a ideologia cientificista da objetividade do conhecimento não atua como interesse. Isto não significa que a Filosofia seja um saber desinteressado. Pelo contrário, é, de todos, o mais interessado, porque o seu interesse está voltado para as questões de fundamento e do valor do conhecimento, tanto no nível dos processos epistemológicos como na esfera do ethos da atividade de conhecer. (LEOPOLDO E SILVA, 1993, p. 804. Grifos do autor)
}

A criticidade ou "força interrogante" é a disposição genuinamente filosófica de não admitir ou de não fazer concessões a respeito de pressupostos insuspeitos. $O$ contributo da filosofia e de seu espírito epistemológico à interdisciplinaridade e à própria formação não se define como transmissão de conhecimento, mas antes como familiarização com uma tradição que é articulada por um modo distinto de pensar, a saber, o pensamento crítico-reflexivo. A busca dos fundamentos do conhecimento, recomeço permanente e marca inconfundível da atitude filosófica, pode e deve perpassar em alguns momentos o processo pedagógico. Afinal, "o que significa a presença da filosofia numa Educação que tenha propósito formador?” (LEOPOLDO E SILVA, 1993, p. 800)

(b) A transversalidade como qualidade filosófica. Dentre as potencialidades de formação interdisciplinar presentes na filosofia, mais do que a criticidade de sua

OLIVEIRA, Cícero. Ensino de filosofia, formação e interdisciplinaridade. Griot : Revista de Filosofia, Amargosa/Bahia, v.17, n.1, p.193-203, junho/2018. 
"força interrogante", importa mobilizar seu esforço de totalidade ou de visão de conjunto. Este esforço que é habitualmente equacionado ao caráter generalista da filosofia, é registro do modo próprio de relação que ela mantém com o saber. Diametralmente oposta à forma de relação com o conhecimento que acima caracterizamos na trilha de Kuhn como "ciência normal", a vinculação filosófica ao saber não pretende separar as dimensões da experiência humana; não é outro o sentido da transversalidade compreendida como qualidade essencialmente filosófica.

Transversalidade é o esforço de totalidade e a qualidade pela qual a filosofia não se fecha sobre si mesma, mas, ao contrário, se abre para e busca a relação com a arte e os mais variados campos de estudo dos fenômenos naturais e sociais que ela efetivamente atravessa, sem com isso pretender diluir suas singularidades.

Para ficarmos com as palavras de Sílvio Gallo, a filosofia implica

$O$ atravessamento mútuo dos campos de saberes, que a partir de suas peculiaridades se interpenetram, se misturam, se mestiçam, sem no entanto perder sua característica própria, que só se amplia em meio a essa multiplicidade. Singularidade de saberes e multiplicidade de campos. [...] Se tomamos a noção de transversalidade apresentada aqui, a noção defendida nos Parâmetros Curriculares Nacionais, de inspiração dos construtivistas espanhóis, parece-me completamente equivocada. Ali a transversalidade aparece como uma forma de realizar a interdisciplinaridade, como um efeito meramente pedagógico, sem a dimensão epistemológica de um trânsito por entre os saberes. No contexto de um currículo disciplinar, a filosofia não pode aparecer apenas "transversalizada"; sem a demarcação daquilo que lhe é específico, não há transversalidade possível; sem a singularidade, perde-se a própria multiplicidade. Isso em termos conceituais. Em termos práticos, sabemos que dizer que a filosofia transversalizada estaria presente em todos os momentos do currículo não passa de uma falácia; nossos professores das diversas disciplinas não são formados para atuar com conhecimentos de filosofia e não teriam condições de fazê-lo. (GALLO, 2006, p. 30-31. Nossos grifos)

Da os riscos de, num currículo disciplinar, elidir da formação a filosofia enquanto disciplina. Se por um lado esse espírito filosófico precisa estimular e permear as estratégias interdisciplinares (pois não se pode consignar somente ao componente curricular de filosofia o embate com a fragmentação cultural), por outro a disciplina filosófica é indispensável como convite permanente e mais profundo para outra forma de imersão relacional com o saber ${ }^{5}$.

Se não se pode com toda segurança consignar à força interrogante (criticidade) e ao esforço de totalidade (transversalidade) constitutivos da filosofia em particular e da atitude filosófica em geral, a reversão das determinações históricas da cultura na contemporaneidade, também não restam dúvidas de que este espírito crítico

5 “Nada mais contrário à Filosofia [...] que o perfilhamento [da tradição de pensamento] se transforme num sistema que encerre a filosofia a ser ensinada." (LEOPLDO E SILVA, 1993, p. 800. Grifos do autor)

OLIVEIRA, Cícero. Ensino de filosofia, formação e interdisciplinaridade. Griot : Revista de Filosofia, Amargosa/Bahia, v.17, n.1, p.193-203, junho/2018. 
reflexivo - compreendido como modo próprio de relação com o saber - tem condições de obstar a pronta aceitação de tais determinações históricas como costuma ocorrer na experiência imediata. É justamente o que se dá quando o processo de ensinoaprendizagem prossegue inadvertidamente sem interpelar sua origem, seu valor e suas consequências ou sem contrastar seus juízos com outras imagens possíveis para a relação como o conhecimento.

Convocar a filosofia na perspectiva de colaboração para a formação interdisciplinar supõe, da parte das estratégias de ensino e da própria interação discente-docente, a superação dos limites disciplinares para a partilha das qualidades do espírito filosófico. Para além do registro disciplinar, a resposta necessária ao desafio de uma nova formação num mundo culturalmente fragmentado exige algo como uma disposição filosófica pedagogicamente alargada. Com efeito, o planejamento educacional interdisciplinar teria poucas oportunidades de efetivação se não encontrasse ressonância na própria formação docente, consciente da fragmentação ${ }^{6}$.

Por fim, cabe observar que a estratégica inserção disciplinar da filosofia numa educação que se pretende interdisciplinar reteria algo de profundamente paradoxal não fosse seu modo próprio de inserção, notadamente distinto das outras disciplinas do currículo. Neste sentido o potencial formador da filosofia que é afeito à "interdisciplinaridade", consiste em tencionar a própria práxis educacional tendencialmente passivo-receptiva em ciências humanas.

O ensino de Filosofia está intimamente associado a uma atitude pedagógico-cultural bem determinada: a de pretender uma articulação sem que esta se dê por meio de uma disciplina especializada na articulação, o que seria transformar a Filosofia numa metodologia abstrata. A Filosofia está inserida no processo educacional como qualquer outra área do saber e não deve ser considerada como uma possibilidade de metalinguagem da Educação. A inserção curricular da Filosofia se distingue da das outras disciplinas na mediada em se pretende algo mais que o processamento da informação e o treinamento do raciocínio. Nas condições atuais, o caráter formador da Filosofia só pode ser pensado numa relação de tensão com a informação e com o treinamento, que esta tensão se manifeste no currículo é algo que deve ser inevitavelmente assumido, já que é esta tensão que abre o espaço para a manifestação da característica formadora da Filosofia. (LEOPOLDO E SILVA, 1993, p. 804. Nossos grifos)

De outra parte, não se pode perder de vista que o influxo do cientificismo e do progresso (enquanto modo de determinada relação com o saber) sobre a autoimagem que nosso tempo faz de si, sugere um impasse muito mais sério e profundamente desafiador a qualquer estratégia de formação interdisciplinar, tanto mais quando tais estratégias apostam minimamente no potencial crítico-reflexivo da formaçãodisposição filosófica aqui referida.

6 Do ponto de vista técnico da gestão pedagógica, um modo válido e de certo modo difundido de elaborar os programas de ensino consiste em estimular a cooperação e a organização dos componentes curriculares sob o eixo unificador dos temas transversais. Contudo, qualquer que seja a estratégia interdisciplinar de ensino, quanto mais distância existir entre suas reais exigências e a formação docente, tanto mais estará suscetível a desviar-se para o formalismo estéril.

OLIVEIRA, Cícero. Ensino de filosofia, formação e interdisciplinaridade. Griot : Revista de Filosofia, Amargosa/Bahia, v.17, n.1, p.193-203, junho/2018. 
Porque o espírito e a atitude filosóficas são incongruentes com o espírito do nosso tempo, qualquer nível de inserção da disciplina e da disposição filosóficas na cultura contemporânea e no currículo escolar, só podem ocorrer à contracorrente do tempo histórico. A notória e ampla recusa social da filosofia como modo nãoaquisitivo, não-instrumental e não-progressista de relação com o conhecimento, está alinhada com a representação que o atual tempo histórico faz de si. 0 desprestígio e a precariedade institucional das ciências humanas e da filosofia, seja no Ensino Médio ou no Superior, são fenômenos sintomáticos da determinação histórico-cultural que aqui apreciamos.

Enquanto não pode prescindir da relação crítico-reflexiva com o saber, a formação interdisciplinar em ciências humanas seguramente encontra aí seu mais vigoroso desafio. É que, para além da ambiência histórica que a possibilita emergir, a desarticulação cultural sobrevive e se dilata também a partir da condição de não ser tensionada, de não pensar a si, de não se interpelar, de não se problematizar; em suma, de seguir incólume ou ao menos sem qualquer perturbação séria. Neste sentido, o espírito filosófico tem uma potencialidade particularmente promissora no que concerne à fragmentação disciplinar nos âmbitos das ciências humanas, dos sabres escolares e universitários. 


\section{Referências bibliográficas}

ARENDT, Hannah. A condição humana. $11^{\text {a }}$ ed. Trad. Roberto Raposo. Rev. e apresentação de Adriano Correia. Rio de Janeiro: Forense Universitária, 2010. GALLO, Sílvio. A filosofia e seu ensino. Conceito e transversalidade. In: Ethica, Rio de Janeiro, V .13, N .1, P .17-35, 2006. p. 17-35.

GARCIA, Lenise Aparecida Martins. Transversalidade e interdisciplinaridade. Rio de Janeiro: $2007 . \quad$ Disponível em: $<$ http://smeduquedecaxias.rj.gov.br/nead/Biblioteca/Forma\%C3\%A7\%C3\%A3o\%2 0 Continuada/Artigos\%20Diversos/garcia-transversalidade-print.pdf $>$. Acesso em 01 jan. 2017.

KANT, Immanuel. Sobre a pedagogia. 3. ed. Trad. Francisco Cock Fontanella. Porto: Editora UNIMEP, 1996.

KUHN, Thomas. A estrutura das revoluções científicas. Trad. Beatriz Vianna Boeira e Nelson Boeira. Rev. de Alice Kyoto Miyashiro.7 ed. São Paulo: Editora Perspectiva, 2003.

LEOPOLDO E SILVA, Franklin. Currículo e formação: o ensino da filosofia. In: Síntese Nova Fase: Belo Horizonte, v. 20, n. 63, 1993, p. 797-806.

NIETZSCHE, Friedrich. Escritos sobre educação. Trad. Noéli Correia de Melo Sobrinho. Rio de Janeiro: Edições Loyola, 2009.

PALÁCIOS, Gonçalo Armijos. Alheio olhar. Goiânia: Editora da UFG, 2004.

PIMENTA, Alessandro. O ensino de filosofia no Brasil: um estudo introdutório sobre sua história, método e pesquisa. In: Cadernos da Funcamp, v. 6, n. 6, 2007. pp. 57-72.

Autor(a) para correspondência: Cícero Oliveira, Universidade Federal do Recôncavo da Bahia, Centro de Formação de Professores, Avenida Nestor de Melo Pita, 535 - Centro, CEP 45300-000, Amargosa BA, Brasil. cicerojsoliveira@ufrb.edu.br 